\title{
Are "fair" wages quantitatively important for business cycle fluctuations in Bulgaria?
}

\section{Aleksandar Vasilev ${ }^{1}$}

\begin{abstract}
We introduce "fair" wages in a general-equilibrium model where worker's effort is unobservable and investigate whether such a mechanism can quantitatively account for the degree of real wage rigidity in the Bulgarian labor markets, as documented in Lozev, Vladova, and Paskaleva (2011) and Paskaleva (2016). In contrast to Danthine and Kurmann (2004), we internalize the effect that past wages have on the current effort level. We calibrate the model to Bulgarian data (1999-2016), and quantify the effect of technological shocks on hours and wages in the theoretical setup. Overall, the calibrated model with "fair" wages performs poorly when it comes to the relative volatilities of labor market variables. This is because aggregate labor market conditions, as proxied by the employment rate and past aggregate wages, turn out not to be quantitatively important for business cycles in Bulgaria.
\end{abstract}

Keywords: Business cycles, unobservable effort, fair wages, unemployment, Bulgaria

JEL Classification: E24, E32, J41

Received: 3 April 2019 / Accepted: 10 December 2019 / Sent for Publication: 12 March 2020

\section{Introduction and Motivation}

In this paper, we investigate the quantitative importance of unobservable worker's effort, and the downward-rigid efficiency ("fair") wages that are introduced as a result of that informational imperfection, in explaining business cycle fluctuations in Bulgaria after the introduction of the currency board arrangement in 1997. Earlier macroeconomic literature, using Dynamic Stochastic General Equilibrium (DSGE) models with perfectly-competitive labor markets, e.g., Vasilev (2009), was not able to capture well the dynamics exhibited by labor market variables (wages, employment, and unemployment) in Bulgaria. That is why we adapt the standard model, and augment it with a plausible mechanism in labor markets that deviates from spot wage contracting, and instead move to setups that emphasize the long-term aspects of the labor arrangement. After all, the employer-employee relationship is a multi-period contract problem. Therefore, an alternative mechanism of wage contracting is considered here, as those mechanisms, mostly

\footnotetext{
${ }^{1}$ Lecturer, Lincoln International Business School, University of Lincoln, UK. E-mail for correspondence: avasilev@lincoln.ac.uk.
}

(C) 2020 by the authors; licensee Review of Economic Perspectives / Národohospodářský obzor, Masaryk University, Faculty of Economics and Administration, Brno, Czech Republic. This article is an open access article distributed under the terms and conditions of the Creative Commons Attribution 3.0 license, Attribution - Non Commercial - No Derivatives. 
based on non-Walrasian settings, are promising areas of research, as pointed in Vasilev (2017c). Similarly, including a government sector, in addition to making the model more realistic, helps the standard Real-Business-Cycle model match data better.

As shown in Paskaleva (2016), real wages in Bulgaria are indeed downward rigid. That is mostly due to collective agreements in place, which prohibit cuts in base wages. Such restrictions mean that adjusting labor costs needs to happen mostly through employment reductions. Lozev, Vladova, and Paskaleva (2011) also document downward real wage rigidity in Bulgaria, even though it is lower than in the other EU member states. We use these empirical findings to motivate our modelling approach here. In contrast to Vasilev (2017b) who introduces wages of no-shirking type a la Shapiro and Stiglitz (1984), and Vasilev (2017c), who incorporated reciprocity arrangement in labor relations and wage determination a la "gift exchange" as in Akerloff (1982), into a relatively standard RBC model with government sector, here we follow Danthine and Kurmann (2004). As in Vasilev $(2017 \mathrm{~b}, \mathrm{c})$, effort will be modelled as a productive input in the firm's production function, but it will be unobservable from the employer's perspective, and thus a contract fully specifying the required level of effort can be neither specified nor enforced. The novelty in this paper is that conditional on working, each household suffers additional dis-utility from exerting effort on the job. However, they will be willing to supply an effort level beyond and above some norm if they feel they have been treated in a fair manner by their employer. The extra effort would come as reciprocation for a wage rate wt above some reference level. In addition, the effort function depends on the overall labor market conditions, the going wage, and past compensation. Allowing effort to depend on past wages helps to introduce sluggishness in wage adjustments in the theoretical framework, and that is what the standard gift exchange model, e.g., Akerlof (1982) lacks.

In addition, Collard and de la Croix (2000) and Danthine and Kurmann (2004) show that including past wage considerations in the reference wage function helps a generalequilibrium macroeconomic model generate substantial downward wage rigidity and improves the overalll statistical fit. In contrast to Danthine and Kurmann (2010), here we stay within the RBC paradigm, and instead of estimating the model, we calibrate it to Bulgarian data for the period 1999-2016, which corresponds to the period of stability after the introduction of the currency board arrangement. In addition, for better realism, we introduce a detailed government sector and analyze the business cycle properties of the model relative to the data in much more detail as compared to earlier studies.

The rest of the paper is organized as follows. Section 2 describes the model. Section 3 described the data used and the calibration procedure. Section 4 presents the long-run theoreticall properties of the model. Section 5 simulates the model and evaluates its business cycle properties vis-a-vis data in the spirit of Canova (2007), especially the response of main variables to an unanticipated technology shock. Section 6 concludes. 


\section{Model Setup}

\section{Description of the model}

There is a continuum of identical one-member households distributed on the $[0,1]$ interval and indexed by $\mathrm{i}$. Each household $i$ derives utility out of consumption and leisure. As in Vasilev (2018), each household $i$ maximizes the following utility function:

$E_{0} \sum_{t=0}^{\infty} \beta^{t}\left\{\ln c_{t}^{i}-h_{t}^{i} G\left(e_{t}^{i}\right)\right\}$

Where $E_{0}$ is the expectation operator conditional on the information available to household $i$ at time $0,0<\beta<1$ denotes the common to all households discount factor, $c_{t}^{i}$ is the consumption of household $\mathrm{i}$ in period $\mathrm{t}, h_{t}^{i}$ is the fraction of time available to household $i$ that is spent working, and $e_{t}^{i}$ is the level of effort exerted. The total time endowment available to each household is normalized to unity, and $l_{t}=1-h_{t}$ is implicitly expressed as time off work.

The novelty in this relatively standard utility function is the last term. In particular, as in Vasilev (2018), conditional on working, each household suffers additional dis-utility from exerting effort on the job. However, they will be willing to supply an effort level beyond and above some norm if they feel they have been treated in a fair manner by their employer. The extra effort would come as reciprocation for a wage wt above some reference level. In addition, the effort function depends on the overall labor market conditions, the going wage, and past compensation - all those factors are empirically supported in surveys, e.g., Bewley (1998).

Following Collard and de la Croix (2000) and Danthine and Kurmann (2007), we express the effort function as

$G\left(e_{t}^{i}\right)=\left[e_{t}^{i}-\left(\phi_{0}+\phi_{1} \ln w_{t}^{i}+\phi_{2} \ln n_{t}+\phi_{3} \ln w_{t}+\phi_{4} \ln w_{t-1}^{i}\right)\right]^{2}$

Where $\phi_{0}, \phi_{1}>0, \phi_{2}, \phi_{3}, \phi_{4}<0, \phi_{1}+\phi_{3}>0, w_{t}^{i}$ is the household's wage in period t, and $w_{t}$ denotes the average wage in the economy.

As in Hansen (1985) and Rogerson (1988) household $i$ 's labor supply is assumed to be indivisible. In equilibrium, as demonstrated in Vasilev (2018), only a fraction $n_{t}$ would be selected to work a full shift in each period t. In order to Pareto-improve the consumption bundle received by both workers and non-workers, a lottery market can be included to provide insurance against unemployment (i.e., not being selected for work) in a certain period. Such an arrangement would achieve full insurance (efficient risk sharing), so everyone would receive the same consumption independent of the employment status. If we assume that all households pool their resources together and maximize aggregate welfare, the resulting discounted utility function becomes as in Danthine and Kurmann (2004):

$\sum_{t=0}^{\infty} \beta^{t}\left\{\ln c_{t}-n_{t} G\left(e_{t}\right)\right\}$ 
Each household starts with $k_{0}^{i}=k_{0}$ initial capital, which is equal to the aggregate capital in period 0 . The aggregate capital stock then evolves as follows:

$k_{t+1}=i_{t}+(1-\delta) k_{t}$

where $0<\delta<1$ denotes the depreciation rate on capital, and $i_{t}$ is investment in period t. The before-tax rental rate on capital is $r_{t}$, and in addition the households have a legal claim on all the firm's profit $\pi_{t}$.

In addition to labor income, households receive labor income as well. The hourly wage rate in the economy is $w_{t}$, so the total before-tax labor income generated in each period is $w_{t} n_{t}$. The aggregate household's budget constraint is then

$\left(1+\tau^{c}\right) c_{t}+k_{t+1}-(1-\delta) k_{t}=\left(1-\tau^{y}\right)\left[r_{t} k_{t}+w_{t} n_{t}+\pi_{t}\right]+g_{t}^{t}$

where $\tau^{c}$ is the consumption tax rate, $\tau^{y}$ is the common income tax rate, and $g_{t}^{t}$ are the aggregate government transfers. The problem now is to maximize (2.3) s.t. (2.5). The first-order optimality conditions are as follows:

$$
\begin{aligned}
& c_{t}: \frac{1}{c_{t}}=\Lambda_{t}\left(1+\tau^{c}\right) \\
& e_{t}: e_{t}=\phi_{0}+\left(\phi_{1}+\phi_{3}\right) \ln w_{t}+\phi_{2} \ln n_{t}+\phi_{4} \ln w_{t-1} \\
& k_{t+1}: \Lambda_{t}=\beta E_{t} \Lambda_{t+1}\left[1-\delta+\left(1-\tau^{y}\right) r_{t+1}\right] \\
& \text { TVC: } \lim _{t \rightarrow \infty} \beta^{t} \Lambda_{t} k_{t+1}=0
\end{aligned}
$$

where $\Lambda \mathrm{t}$ is the Lagrangian multiplier attached to the household's budget constraint in period t. The first optimality condition equates the marginal utility of consumption to the marginal utility of wealth. The second condition is called the Effort Condition (EC), or Solow (1979) condition. (Note that we have imposed the fact that in this economy everyone is identical, so the individual and the average wages are the same.) In other words, the optimal effort level depends on the changes in current and past wage rate, and current employment. The third condition is the employment optimality condition. The fourth is the so called Euler equation, which describes the optimal allocation of capital in any two congruent periods. The last condition, the Transversality condition (TVC), is a boundary condition that needs to be imposed to eliminate explosive solutions. 
Firm

There is a stand-in firm that produces a homogeneous final good that can be used for consumption, investment, or government purchases. The Cobb-Douglas production function uses physical capital and efficiency labor as inputs an is as follows:

$y_{t}=A_{t} k_{t}^{1-\alpha}\left(e_{t} n_{t}\right)^{\alpha}$

where $A_{t}$ captures the level of technology, $0<\alpha, 1-\alpha<1$ are the efficiency labor and capital shares, respectively.

The firm maximizes profit subject to the household's participation condition and effort conditionn being satisfied, which turns the firm's problem becomes dynamic. More specifically, this is because the wage set today influences effort next period through the existence of past wage, wt-1 as an argument in the effort condition. The firm discounts profit by the stochastic discount factor (expressed in utility terms) $\Lambda_{t}=1 /\left[\left(1+\tau^{c}\right) c_{t}\right]$, hence the firm's dynamic problem is as follows:

$\max \sum_{t=0}^{\infty} \beta^{t} \Lambda_{t}\left\{y_{t}-w_{t} n_{t}-r_{t} k_{t}\right\}$

The resulting first-order conditions are

$k_{t}:(1-\alpha) \frac{y_{t}}{k_{t}}=r_{t}$

$n_{t}: \alpha \frac{y_{t}}{n_{t}}+\alpha \frac{y_{t}}{e_{t}} \frac{\partial e_{t}}{\partial n_{t}}=w_{t}$

$w_{t}: \alpha \frac{y_{t}}{e_{t}}+\beta \frac{\Lambda_{t+1}}{\Lambda_{t}} \quad \alpha \frac{y_{t+1}}{e_{t+1}} \frac{\partial e_{t+1}}{\partial w_{t}}$

where (2.13) and (2.14) make use of the fact that effort responds to the current and past wage rates. The first condition describes optimal renting of capital: in equilibriumm it receives its marginal product. The second condition characterizes labor demand by the firm: in this setup, there is an elasticity term, $\left(\frac{\partial e}{\partial n}\right)\left(\frac{n}{e}\right) \geq 0$, which appears to capture the effect of a new margin of adjustment. More specifically, a higher level of employment, though costly in terms of labor productivity, may actually increase the value of the firm's investment and in turn worker's effort; Using an analogy from finance, from the firm's point of view, the worker is a multi-period asset. In other words, given the dynamic implications of the wage on the effort level exerted, the firm is hiring more people as compared to the perfectly competitive, perfect effort observability case.

The last equation describes how efficiency wages are set, i.e., how the firm chooses a wage rate to inspire the worker to supply optimum effort. Combining the optimality condition for employment and wages produces as in Vasilev (2017c):

$1=\epsilon\left(e_{t}, w_{t}\right)-\epsilon\left(e_{t}, n_{t}\right)+\beta E_{t}\left[\frac{\Lambda_{t+1}}{\Lambda_{t}} \frac{y_{t+1}}{y_{t}} \epsilon\left(e_{t+1}, w_{t}\right)\right]$ 
Where $\epsilon\left(e_{t}, w_{t}\right)$ denotes the elasticity of effort level with respect to the wage rate, and $\epsilon\left(e_{t+1}, w_{t}\right)$ denotes the elasticity of the next-period effort level with respect to the current wage. With $\epsilon$ (et, wt) $>0$, the standard Solow (1979) condition does not apply, since an increase in the wage rate at the margin produces an extra increase in worker's productivity; similarly, with $\mathrm{c}(\mathrm{et}+1, \mathrm{wt})<0$, the firm has to take into consideration the futuree effect of the current wage rate - that a higher wage paid today makes it more costly to extract higher effort from a worker in the future.

Given the assumed functional form, we can now solve for the optimal effort level to obtain

$e_{t}=\phi_{1}+\phi_{3}-\phi_{2}+\beta \phi_{4}=\bar{e}>0$

That effort is positive and constant over the cycle. Next, plugging that expression into the effort function yields

$\ln w_{t}=\gamma_{0}+\gamma_{1} \ln n_{t}+\gamma_{2} \ln w_{t-1}$

where

$\gamma_{0}=\frac{\phi_{1}+\phi_{3}-\phi_{2}+\beta \phi_{4}-\phi_{0}}{\phi_{1}+\phi_{3}}, \gamma_{1}=-\frac{\phi_{2}}{\phi_{1}+\phi_{3}}, \gamma_{2}=-\frac{\phi_{4}}{\phi_{1}+\phi_{3}}$

which differs from Danthine and Kurmann (2004); Here we are following Danthine and Kurmann (2010), and internalize the effect that past wages have on current effort level, which is the more realistic case.

\section{Government}

The government will be assumed to be running a balanced budget in every period. The government collects revenue from levying taxes on capital, labor, and profit income, and then spends on government consumption and transfers, which are returned lumpsum to the households:

$\tau^{c} c_{t}+\tau^{y}\left[r_{t} k_{t}+w_{t} n_{t}+\pi_{t}\right]=g_{t}^{c}+g_{t}^{t}$

Where $g_{t}^{c}$ are (non-productive) government purchases. Government spending share will be set equal to its long-run average so that the level will be varying with output. Government transfers will be residually determined and will always adjust to make sure that the government budget is balanced.

\section{Stochastic Processes for the exogenous variables}

The first exogenous stochastic variable is total factor productivity At, which is assumed to follow AR(1) processes in logs, in particular

$\ln A_{t+1}=\left(1-\rho_{a}\right) \ln A_{0}+\rho_{a} \ln A_{t}+\varepsilon_{t+1}^{a}$

where $A=A_{o}>0$ is the steady-state level of total factor productivity process, $0<\rho \mathrm{a}<$ 1 is the first-order autoregressive persistence parameter and $\varepsilon_{t+1}^{a} \sim \operatorname{iidN}\left(0, \sigma^{2}\right)$ are ran- 
dom shocks to the total factor productivity process. Hence, the innovations to technology represent unexpected changes in the total factor productivity process.

\section{Decentralized Dynamic Equilibrium with fair wages}

Given the process followed by total factor productivity $\left\{A_{t}\right\}_{t=0}^{\infty}$, the tax $\operatorname{rates}\left\{\tau^{c}, \tau^{y}\right\}$, initial capital stock $k_{0}$, hours worked per household $h^{i}$, the decentralized dynamic equilibrium with fair wages is a list of sequences $\left\{c_{t}, i_{t}, k_{t}, e_{t}\right\}_{t=0}^{\infty}$ for each household $\mathrm{i}$, input levels $\left\{k_{t}, n_{t}, e_{t}\right\}_{t=0}^{\infty}$ chosen by the firm, a sequence of government spending categories $\left\{g_{t}^{c}, g_{t}^{t}\right\}_{t=0}^{\infty}$ and input prices $\left\{w_{t}, r_{t}\right\}_{t=0}^{\infty}$ such that (i) each household i maximizes its utility function subject to its budget constraint; (ii) the representative firm maximizes profit by offering a wage schedule that satisfies the workers' incentive compatibility constraint and to induce an optimal effort level; (iii) government budget is balanced in each period; (iv) all markets clear.

\section{Data and model calibration}

To characterize business cycle fluctuations in Bulgaria, we will focus on the period following the introduction of the currency board (1999-2016). Quarterly data on output, consumption, and investment was collected from the National Statistical Institute (2017), while the real interestt rate is taken from Bulgarian National Bank Statistical Database (2017). The calibration strategy described in this section follows a longestablished tradition in modern macroeconomicss: first, as in Vasilev (2016), the value of the discount factor, $\beta=0.982$, is set to match the steady-state capital-to-output ratio in Bulgaria, $\mathrm{k} / \mathrm{y}=13.964$, in the steady-state Euler equation. The labor share parameter, $\alpha=0.571$, is obtained as in Vasilev (2017d), and equals the average value of labor income in aggregate output over the period 1999-2016. This value is slightly higher as compared to other studies on developed economies, due to the overaccumulation of physical capital, which was part of the ideology of the totalitarian regime, which was in place until 1989. Next, the average income tax rate was set to $\tau y=0.1$. This is the average effective tax rate on income between 1999-2007 when Bulgaria used progressive income taxation, and equal to the proportional income tax rate introduced as of 2008 . Similarly, the tax rate on consumption is set to its value over the period, $\tau c=0.2$. This is in line with the estimates for Bulgaria (Vasilev 2017a) as well over the period studied.

Next, the steady-state depreciation rate of physical capital in Bulgaria, $\delta=0.013$, was taken from Vasilev (2016). It was estimated as the average quarterly depreciation rate over the period 1999-2014. Next, the steady state employment rate in Bulgaria is set to $\mathrm{n}=0.533$, as in Vasilev (2016a). Following Vasilev (2017c), the values for $\gamma 1$ and $\gamma 2$ were estimated from the optimized effort function. Finally, the processes followed by total factor productivity (TFP) is estimated from the detrended series by running an $\mathrm{AR}(1)$ regression and saving the residuals. Table 1 below summarizes the values of all model parameters used in the paper. 


\section{Table 1. Model Parameters}

\begin{tabular}{lcll} 
Param & Value & Description & Method \\
\hline$\beta$ & 0.982 & Discount factor & Calibrated \\
$\alpha$ & 0.571 & Labor Share & Data avg. \\
$\delta$ & 0.013 & Depreciation rate on physical capital & Data avg. \\
$\mathrm{n}$ & 0.533 & Employment rate & Data avg \\
$\gamma 1$ & 0.140 & Weight on labor market conditions & Estimated \\
$\gamma 2$ & 0.814 & Weight attached to past wage & Estimated \\
$\tau y$ & 0.100 & Average tax rate on income & Data avg. \\
$\tau \mathrm{c}$ & 0.200 & VAT/consumption tax rate & Data avg. \\
$\rho \mathrm{a}$ & 0.701 & AR(1) persistence coefficient, TFP & Estimated \\
$\sigma \mathrm{a}$ & 0.044 & st. error, TFP process & Estimated
\end{tabular}

Source: Author's calculations

\section{Steady-State}

Once the values of model parameters were obtained, the steady-state equilibrium system solved, the "big ratios" can be compared to their averages in Bulgarian data. The results are reported in Table 2 on the next page. The steady-state level of output was normalized to unity (hence the level of technology A differs from unity), which greatly simplified the computations, and allows the steady-state to be solved by hand. Next, the model matches consumption-to-output ratio by construction; The investment and government purchases ratios are also closely approximated. The shares of income are also identical to those in data, which follows directly from the constant-returns to scale featured by the aggregate production function. The after-tax return, where $r^{\sim}=(1-\tau y)-\delta$ is also relatively well- captured by the model.

Table 2. Data Averages and Long-run Solution

\begin{tabular}{llll}
\hline Variable & Description & Data & Model \\
\hline $\mathrm{y}$ & Steady-state output & N/A & 1.000 \\
$\mathrm{c} / \mathrm{y}$ & Consumption-to-output ratio & 0.648 & 0.674 \\
$\mathrm{i} / \mathrm{y}$ & Investment-to-output ratio & 0.201 & 0.175 \\
$\mathrm{k} / \mathrm{y}$ & Capital-to-output ratio & 13.96 & 13.96 \\
$\mathrm{gc} / \mathrm{y}$ & Government consumption-to-output ratio & 0.151 & 0.151 \\
$\mathrm{wh} / \mathrm{y}$ & Labor income-to-output ratio & 0.571 & 0.571 \\
$\mathrm{rk} / \mathrm{y}$ & Capital income-to-output ratio & 0.429 & 0.429 \\
$\mathrm{~h}$ & Share of time spent working & 0.333 & 0.333 \\
$\mathrm{rb}$ & After-tax net return on capital/bond rate & 0.014 & 0.016
\end{tabular}

Source: Author's calculations. 


\section{Out of steady-state model dynamics}

Since the model does not have an analytical solution for the equilibrium behavior of variables outside their steady-state values, we need to solve the model numerically. This is done by log-linearizing the original equilibrium (non-linear) system of equations around the steady-statee. This transformation produces a first-order system of stochastic difference equations. First, we study the dynamic behavior of model variables to an isolated shock to the total factor productivity process, and then we fully simulate the model to compare how the second moments of the model perform when compared against their empirical counterparts.

\section{Impulse Response Analysis}

This subsection documents the impulse responses of model variables to a $1 \%$ surprise innovation to technology. The impulse response functions (IRFs) are presented in Fig. 1 on the next page. As a result of the one-time unexpected positive shock to total factor productivity, output increases upon impact. This expands the availability of resources in the economy, so use of output - consumption, investment, and government consumption also increase con- contemporaneously.

At the same time, the increase in productivity increases the after-tax return on the two factors of production, labor, and capital. The representative households then respond to the incentives contained in prices and start accumulating capital, and supplies more hours worked. In turn, the increase in capital input feeds back in output through the production function, and that further adds to the positive effect of the technology shock. In the labor market, the wage rate increases, and the household increases its hours worked. In turn, the increase in total hours further increases output, again indirectly.

Over time, as capital is being accumulated, its after-tax marginal product starts to decreasee, which lowers the households' incentives to save. As a result, the physical capital stock eventually returns to its steady-state and exhibits a hump-shaped dynamics over its transitionn path. The rest of the model variables return to their old steady-states in a monotone fashion as the effect of the one-time surprise innovation in technology dies out.

\section{Simulation and moment matching}

As in Vasilev (2017b), we will now simulate the model 10,000 times for the length of the data horizon. Both empirical and model simulated data is detrended using the Hodrick-Prescott (1980) filter. Table 3 on the next page summarizes the second moments of data (relative volatilities to output, and contemporaneous correlations with output) versus the same moments computed from the model-simulated data at a quarterly frequency. To minimize the sampling error, the simulated moments are averaged out over the computer-generated draws. As in Vasilev (2016, 2017b, 2017c), the model matches quite well the absolute volatility of output. By construction, government consumption in the model varies as much as output. The model overestimates the variability in consumption, and less so, the predicted volatility of the investment. Still, the model is qualitatively consistent with the stylized fact that consumption generally varies less than output, while investment is more volatile than output. 
Figure 1. Impulse Responses to a 1\% surprise innovation in technology
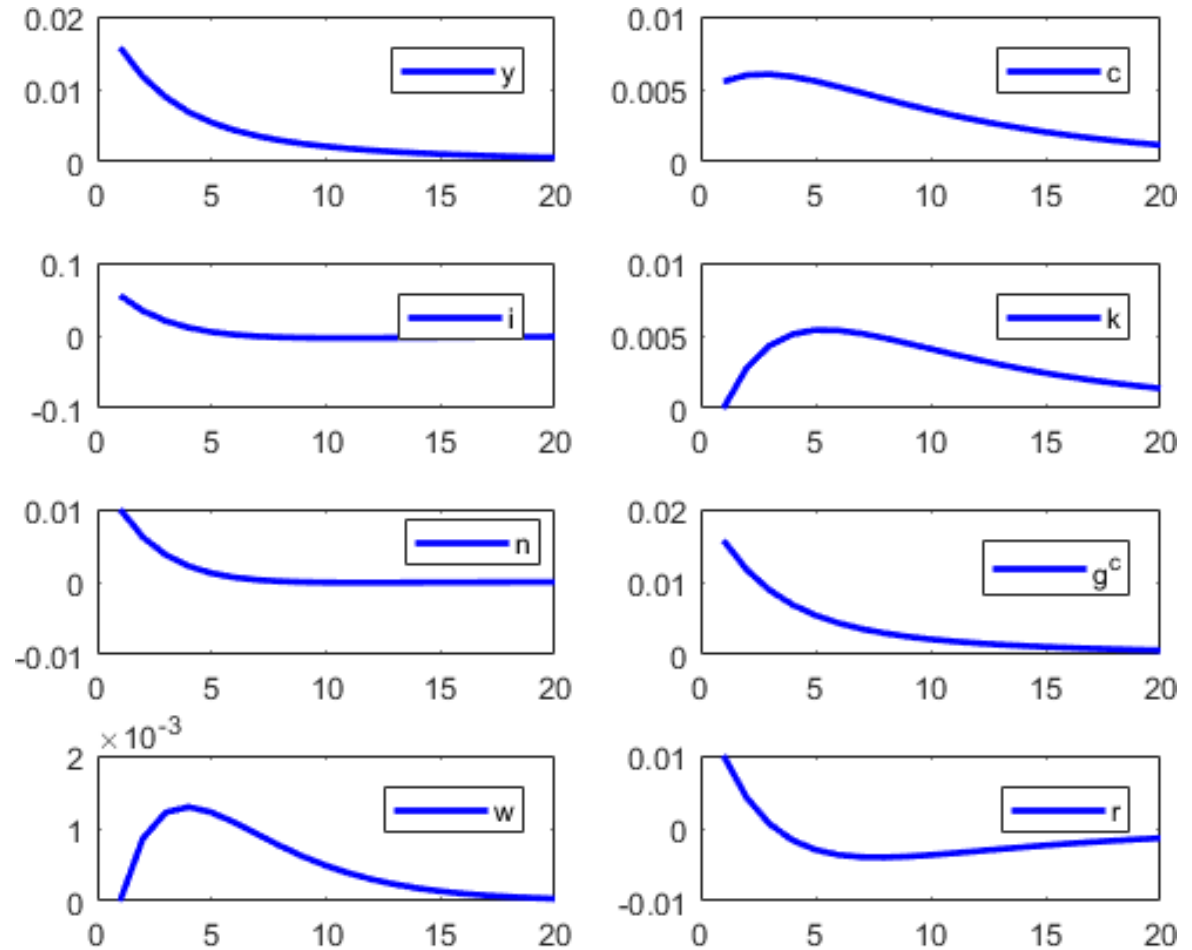

Source: Author's calculation

With respect to the labor market variables, the variability of employment, unemployment, and wages predicted by the model is too low than that in data. This is a confirmation that the incentive wage function, when calibrated to Bulgarian data, does not describe very well the dynamics of labor market variables after the introduction of the currency board. Next, in terms of contemporaneous correlations, the model systematically over-predicts the procyclicalityy of the main aggregate variables - investment, and government consumption. This, however, is a common limitation of this class of models. With respect to wages, the model predicts strong cyclicality, while wages in data are acyclical. This shortcoming is well-known in the literature and an artifact of the wage following closely labor productivity in the model. In the next subsection, as in Vasilev (2016), we investigate the dynamic correlation between labor market variables at different leads and lags, thus evaluating how well the model matches the phase dynamics among variables. In addition, the autocorrelation functions (ACFs) of empirical data, obtained from an unrestricted VAR(1) are put under scrutiny and compared and contrasted to the simulated counterparts generated from the model. 
Table 3. Business Cycle Moments

\begin{tabular}{lll}
\hline & Data & Model \\
\hline$\sigma_{y}$ & 0.05 & 0.05 \\
$\sigma_{c} / \sigma_{y}$ & 0.55 & 0.90 \\
$\sigma_{i} / \sigma_{y}$ & 1.77 & 1.92 \\
$\sigma_{g} / \sigma_{y}$ & 1.21 & 1.00 \\
$\sigma_{h} / \sigma_{y}$ & 0.63 & 0.37 \\
$\sigma_{w} / \sigma_{y}$ & 0.83 & 0.14 \\
$\sigma_{y} / h / \sigma_{y}$ & 0.86 & 0.14 \\
$\sigma_{u} / \sigma_{y}$ & 3.22 & 0.37 \\
\hline $\operatorname{corr}(c, y)$ & 0.85 & 0.93 \\
$\operatorname{corr}(i, y)$ & 0.61 & 0.80 \\
$\operatorname{corr}(g, y)$ & 0.31 & 1.00 \\
$\operatorname{corr}(h, y)$ & 0.49 & 0.93 \\
$\operatorname{corr}(w, y)$ & -0.01 & 0.96 \\
$\operatorname{corr}(u, y)$ & -0.47 & -0.82 \\
\hline
\end{tabular}

Source: Author's calculation

\section{Auto- and cross-correlations}

This subsection discusses the auto-(ACFs) and cross-correlation functions (CCFs) of the major model variables. The coefficients' empirical ACFs and CCFs at different leads and lags are presented in Table 4 below against the averaged simulated AFCs and CCFs. Following Canova (2007), this is used as a goodness-of-fit measure.

Table 4: Autocorrelations for Bulgarian data and the model economy

\begin{tabular}{|c|c|c|c|c|c|}
\hline & & $\mathrm{k}$ & & & \\
\hline Method & Statistic & 0 & 1 & 2 & 3 \\
\hline Data & $\operatorname{corr}\left(u_{t}, u_{t-k}\right)$ & 1.000 & 0.765 & 0.552 & 0.553 \\
\hline \multirow[t]{2}{*}{ Model } & $\operatorname{corr}\left(u_{t}, u_{t-k}\right)$ & 1.000 & 0.954 & 0.898 & 0.833 \\
\hline & (s.e.) & $(0.000)$ & $(0.028)$ & $(0.055)$ & $(0.080)$ \\
\hline
\end{tabular}




\begin{tabular}{|c|c|c|c|c|c|}
\hline Data & $\operatorname{corr}\left(n_{t}, n_{t-k}\right)$ & 1.000 & 0.484 & 0.009 & 0.352 \\
\hline \multirow[t]{2}{*}{ Model } & $\operatorname{corr}\left(n_{t}, n_{t-k}\right)$ & 1.000 & 0.954 & 0.898 & 0.833 \\
\hline & (s.e.) & $(0.000)$ & $(0.028)$ & $(0.055)$ & $(0.080)$ \\
\hline Data & $\operatorname{corr}\left(y_{t}, y_{t-k}\right)$ & 1.000 & 0.810 & 0.663 & 0.479 \\
\hline \multirow[t]{2}{*}{ Model } & $\operatorname{corr}\left(y_{t}, y_{t-k}\right)$ & 1.000 & 0.957 & 0.906 & 0.847 \\
\hline & (s.e.) & $(0.000)$ & $(0.027)$ & $(0.051)$ & $(0.075)$ \\
\hline Data & $\operatorname{corr}\left(a_{t}, a_{t-k}\right)$ & 1.000 & 0.702 & 0.449 & 0.277 \\
\hline \multirow[t]{2}{*}{ Model } & $\operatorname{corr}\left(a_{t}, a_{t-k}\right)$ & 1.000 & 0.956 & 0.903 & 0.840 \\
\hline & (s.e.) & $(0.000)$ & $(0.027)$ & $(0.053)$ & $(0.077)$ \\
\hline Data & $\operatorname{corr}\left(c_{t}, c_{t-k}\right)$ & 1.000 & 0.971 & 0.952 & 0.913 \\
\hline \multirow[t]{2}{*}{ Model } & $\operatorname{corr}\left(c_{t}, c_{t-k}\right)$ & 1.000 & 0.958 & 0.909 & 0.853 \\
\hline & (s.e.) & $(0.000)$ & $(0.026)$ & $(0.049)$ & $(0.072)$ \\
\hline Data & $\operatorname{corr}\left(i_{t}, i_{t-k}\right)$ & 1.000 & 0.810 & 0.722 & 0.594 \\
\hline \multirow[t]{2}{*}{ Model } & $\operatorname{corr}\left(i_{t}, i_{t-k}\right)$ & 1.000 & 0.953 & 0.894 & 0.825 \\
\hline & (s.e.) & $(0.000)$ & $(0.029)$ & $(0.056)$ & $(0.082)$ \\
\hline Data & $\operatorname{corr}\left(w_{t}, w_{t-k}\right)$ & 1.000 & 0.760 & 0.783 & 0.554 \\
\hline \multirow[t]{2}{*}{ Model } & $\operatorname{corr}\left(w_{t}, w_{t-k}\right)$ & 1.000 & 0.958 & 0.906 & 0.846 \\
\hline & (s.e.) & $(0.000)$ & $(0.027)$ & $(0.051)$ & $(0.075)$ \\
\hline
\end{tabular}

Source: Author's calculation

As seen from Table 4 above, the model compares relatively well vis-a-vis data. Empirical ACFs for output and investment are slightly outside the confidence band predicted by the model, while the ACFs for total factor productivity and household consumption are well- approximated by the model. The persistence of labor market variables is also relatively well-described by the model dynamics. Overall, the model with habits in consumption generatess too much persistence in output and both employment and unemployment, and is subject to the criticism in Nelson and Plosser (1992), Cogley and Nason (1995) and Rotemberg and Woodford (1996b), who argue that the RBC class of models do not have a strong internal propagation mechanism besides the strong persistence in the TFP process. In those modelss, e.g., Vasilev (2009), and in the current one, labor market is modelled in the Walrasian market-clearing spirit, and output and unemployment persistence are low. 
Next, as seen from Table 5 below, over the business cycle, in data labor productivity leads employment. The model, however, cannot account for this fact, despite the dependence of the wage function on its lagged value. As in the standard RBC model a technology shock can be regarded as a factor shifting the labor demand curve, while holding the labor supply curve constant. Therefore, the effect between employment and labor productivity is only a contemporaneous one.

Table 5. Dynamic correlations for Bulgarian data and the model economy

\begin{tabular}{|c|c|c|c|c|c|c|c|c|}
\hline & & $\mathrm{k}$ & & & & & & \\
\hline Method & Statistic & -3 & -2 & -1 & 0 & 1 & 2 & 3 \\
\hline Data & $\operatorname{corr}\left(n_{t},(y / n)_{t-k}\right)$ & -0.342 & -0.363 & -0.187 & -0.144 & 0.475 & 0.470 & 0.346 \\
\hline \multirow[t]{2}{*}{ Model } & $\operatorname{corr}\left(n_{t},(y / n)_{t-k}\right)$ & 0.081 & 0.104 & 0.133 & 0.819 & 0.288 & 0.183 & 0.106 \\
\hline & (s.e.) & $(0.314)$ & $(0.273)$ & $(0.227)$ & $(0.149)$ & $(0.240)$ & $(0.272)$ & $(0.303)$ \\
\hline Data & $\operatorname{corr}\left(n_{t}, w_{t-k}\right)$ & 0.355 & 0.452 & 0.447 & 0.328 & -0.040 & -0.390 & -0.57 \\
\hline \multirow[t]{2}{*}{ Model } & $\operatorname{corr}\left(n_{t}, w_{t-k}\right)$ & 0.081 & 0.104 & 0.133 & 0.819 & 0.288 & 0.183 & 0.106 \\
\hline & (s.e.) & $(0.314)$ & $(0.273)$ & $(0.227)$ & $(0.149)$ & $(0.240)$ & $(0.272)$ & $(0.303)$ \\
\hline
\end{tabular}

\section{Conclusions}

In this paper, we investigate the quantitative importance of "fair" wages in explaining fluctuations in Bulgarian labor markets. In contrast to Vasilev (2017b) who introduces wages of no-shirking type a la Shapiro and Stiglitz (1984), and Vasilev (2017c), who incorporated reciprocity arrangement in labor relations and wage determination a la "gift exchange" as in Akerloff (1982), into a relatively standard RBC model with government sector, here we follow Danthine and Kurmann $(2004,2010)$. We calibrated the model to Bulgarian data after the introduction of the currency board arrangement and studied the impulse responses of aggregate variables in the face of exogenous technological shocks. Overall, the calibrated model with "fair" wages performs poorly when it comes to the relative volatilities of labor market variables. This is because aggregate labor market conditions, as proxied by the employmentt rate in the economy, turn out to be of lesser importance. As suggested in Vasilev (2017c), rent-sharing aspects, and firms' ability to pay, are the most important determinants of wages in Bulgaria over the period 1999-2015. Similar findings have been documented in Lozev, Vladova and Paskaleva (2011) and Paskaleva (2016).

Disclosure statement: No potential conflict of interest was reported by the author. 


\section{References}

AKERLOF, G.A., (1982) Labor contracts as partial gift exchange, Quarterly Journal of Economics 97: 543-569. DOI: 10.2307/1885099

BEWLEY, T.F., (1998). Why not cut pay?, European Economic Review 42(3-5): 459490.

Bulgarian National Bank, (2017), Bulgarian National Bank Statistics (www.bnb.bg). Accessed on Oct. 21, 2017.

CANOVA, F., (2007), Methods for Applied Macroeconomic Research. Princeton University Press: Princeton, NJ.

COGLEY, T., NASON, J., (1995). Output dynamics in Real-Business-Cycles, American Economic Review 85(3): 492-511.

COLLARD, F., de la CROIX, D. (2000), Gift exchange and the business cycle: the fair wage strikes back, Review of Economic Dynamics 3, 166-193. DOI: $\underline{10.1006 / \text { redy. } 1999.0075}$

DANTHINE, J. P., KURMANN, A., (2004), Fair wages in a New Keynesian model of the business cycle, Review of Economic Dynamics 7: 107-142. DOI: 10.1016/j.red.2003.07.001

DANTHINE, J. P., KURMANN, A., (2007), The Macroeconomic Consequences of Reciprocity in Labor Relations, Scandinavian Journal of Economics 109(4): 857881.DOI: 10.1111/j.1467-9442.2007.00518.x

DANTHINE, J. P., KURMANN, A., (2010), The Business Cycle Implications of Reciprocity in Labor Relations, Journal of Monetary Economics 57(7): 837-850. DOI: 10.1016/j.jmoneco.2010.08.006

HANSEN, G. (1985), Indivisible labor and the business cycle. Journal of Monetary Economics, Vol. 16, pp. 309-327. DOI: 10.1016/0304-3932(85)90039-X

HODRICK, Robert and Edward PRESCOTT (1980), Post-war US business cycles: An empirical investigation., Unpublished manuscript (Carnegie-Mellon University, Pittsburgh, PA).

LOZEV, I., Z., VLADOVA, Z., PASKALEVA, D., (2011), Wage-setting behaviour of Bulgarian firms: Evidence from survey data, Discussion Paper 87, Bulgarian National Bank, Sofia, Bulgaria.

National Statistical Institute (2017) NSI Statistical Database. Available on-line at www.nsi.bg. Last accessed on Dec. 18, 2017.

NELSON, C. R. and C.I. PLOSSER (1982), Trends and Random Walks in Macroeconomic Time Series, Journal of Monetary Economics 10(2): 139-62. DOI: 10.1016/0304$\underline{3932(82) 90012-5}$

PASKALEVA, D., (2016), Labour cost and price adjustment practices of Bulgarian firms in the period 2009-13, Discussion Paper 101, Bulgarian National Bank, Sofia, Bulgaria. 
ROGERSON, R., (1988), Indivisible labor, lotteries and equilibrium. Journal of Monetary Economics 21: 3-16. DOI: 10.1016/0304-3932(88)90042-6

ROTEMBERG, J., WOODFORD. M., (1996), Real-Business-Cycle Models and the Fore- castable Movements in Output, Hours, and Consumption, American Economic Review, 86: 71-89.

SHAPIRO, C., STIGLITZ, J.E., (1984), Equilibrium Unemployment as a workerdiscipline de- vice, American Economic Review 74: 433-444.

SOLOW, R.M., (1979), Another Possible Source of Wage Rigidity, Journal of Macroeconomics 1: 79-82. DOI: $\underline{10.1016 / 0164-0704(79) 90022-3}$

VASILEV, A., (2009), Business cycles in Bulgaria and the Baltic countries: an RBC approach, International Journal of Computational Economics and Econometrics, 1(2): 148-170. DOI: 10.1504/IJCEE.2009.029256

VASILEV, A., (2015a), Welfare effects of at income tax reform: the case of Bulgaria, Eastern European Economics 53(2): 205-220. DOI: 10.1080/00128775.2015.1033364

VASILEV, A., (2015b), Welfare gains from the adoption of proportional taxation in a general- equilibrium model with a grey economy: the case of Bulgaria's 2008 flat tax reform, Economic Change and Restructuring, 48(2): 169-185.

VASILEV, A., (2016), Search and matching frictions and business cycle fluctuations in Bul- garia, Bulgarian Economic Papers BEP 03-2016, Center for Economic Theories and Policies, Sofia University St. Kliment Ohridski, Faculty of Economics and Business Administration, Sofia, Bulgaria.

VASILEV, A., (2017a), Business Cycle Accounting: Bulgaria after the introduction of the currency board arrangement (1999-2014), European Journal of Comparative Economics, 14(2): 197-219.

VASILEV, A. (2017b), A Real-Business-Cycle model with efficiency wages and a government sector: the case of Bulgaria, Central European Journal of Economics and Econometrics, 9(4): 359-377.

VASILEV, A., (2017c), A Real-Business-Cycle model with reciprocity in labor relations and fiscal policy: the case of Bulgaria, Bulgarian Economics Papers 03-2017, Center for Economic Theories and Policies, Sofia University St. Kliment Ohridski, Sofia, Bulgaria.

VASILEV, A., (2017d), VAT Evasion in Bulgaria: A General-Equilibrium Approach, Review of Economics and Institutions, 8(2): 2-17. DOI: 10.5202/rei.v8i2.243

VASILEV, A.Z., (2018), Aggregation with a non-convex labor supply decision, unobservable effort, and incentive ("fair") wages, Theoretica l and Practical Research in Economic Fields, Volume IX, Issue 2(18): 144-147. 